\title{
Food choice, appetite and physical activity
}

\author{
France Bellisle* \\ INSERM U34 1 and Service de Nutrition, Hôtel-Dieu, 1, Place du Parvis Notre-Dame, 75181 Paris cedex 04, \\ France
}

Accepted: 15 May 1999

\begin{abstract}
Food choices and diet composition have been studied less often than energy intake in subjects with varying levels of physical activity. The reported effects of exercise on food choices are not fully consistent, especially on the short term. Type of exercise, intensity, duration can affect the results as well as subjects' characteristics (gender, age, previous training and fitness). A crucial role could also be played by psychological (chronic dieting, attitudes toward health and food, long-established food habits and preferences) and social (traditions, food availability, appropriate times and places) factors. In short-term intervention studies, where a meal is ingested a few minutes following a bout of exercise of varying duration and intensity, an increase in $\mathrm{CHO}$ intake is most often reported, while increased protein intake is an occasional observation. In long-term (several weeks) training interventions, intake is assessed from dietary records. Again CHO intake is augmented in exercised subjects as compared to controls, while that of saturated fats and cholesterol may also be affected. Epidemiological studies (without dietary or exercise intervention) often report that habitually active persons eat more and ingest more fruits and vegetables than less active peers. It is not known to what extent such food choices are driven by biological needs (e.g. replacement of glycogen) or elicited by social and psychological factors.
\end{abstract}

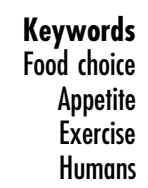

\section{Key messages}

- There is no scientific evidence that exercise increases hunger, but very intense exercise may suppress it transitorily.

- Physical activity is just one of the numerous factors that determine energy balance in humans. Habits, preferences, social and psychological factors seem to exert much stronger effects on food choice and intake than immediate cues originating from a bout of moderate exercise. The energy density of the foods available after exercise is a more potent predictor of final energy balance than the amount of energy spent during exercise.

- Food intake surveys have reported that active persons ingest large amounts of carbohydrates, in the form of fruits, vegetables and cereal products. It is not clear whether such food choices are determined by the metabolic effects of exercise or by knowledge and beliefs about appropriate nutrition in health-concerned individuals.

\section{Introduction}

Activity, or inactivity, is a crucial element of lifestyle. It has powerful effects on health and well-being. It is a popular belief that exercise stimulates appetite and then intake. Such a notion is also defended in scientific texts ${ }^{1}$, suggesting for example that encouraging elderly persons to exercise is a proper way to stimulate their appetite. Several recent review articles ${ }^{2-8}$ report little coupling between the amount of energy expended by exercise and energy intake. However, participation in sports or habitual activity (e.g. walking to work as opposed to driving; climbing stairs as opposed to using lifts, etc.) can have other effects, such as changes in the motivation to eat, different selection of foods, different sensitivity to sensory cues, etc.

\section{Methodological concerns}

Investigating the relationships between exercise and nutritional intake requires several dependable tools. Precise measurements can be obtained when both exercise and intake are performed under laboratory conditions. However, this situation is artificial and it is not known how well it generalizes to every day life.

To assess the relationships between habitual activity and food intake in free-living humans, questionnaires are used to evaluate both aspects of the subjects' lifestyle. Food intake questionnaires have been criticized because of the potentially important level of under-reporting revealed when comparing declared intake to valid measurements of energy expenditure? 
Questionnaires for assessing activity level provide a crude estimation of energy expenditure but their validity begins to be recognized ${ }^{10}$. Studies in freeliving subjects clearly trade some accuracy and some validity for a closer look at habitual behaviour.

\section{Determinants of food intake in humans}

Numerous factors determine food intake in humans, so that exercise will at best contribute to the control of intake, along with very robust influences such as lifelong habits, preferences and aversions, social facilitation, immediate or permanent psychological and behavioural characteristics, etc. A laboratory context involves additional constraints, for example limited food choices.

Several potent factors are from extra-physiological origin. They can be overcome to some degree by manipulations of the physiological state of the subject, for example by food deprivation prior to the experimental meal ${ }^{11}$. In this situation, subjects respond to deprivation by increased intake. However, a change in the nutritional state of the organism induced by exercise clearly exerts no dramatic effect on intake, at least in terms of energy ${ }^{6}$.

\section{Appetite and preferences}

There is little evidence that the drive to eat is augmented after exercise. Typically, no increase in hunger is reported as a result of exercise-induced energy deficit ${ }^{12-19}$. By contrast, a bout of intense exercise may suppress hunger for a very short period of time ${ }^{13,16,17,20}$. Such 'exercise-induced anorexia' is well documented, but experts consider that its very short duration (about one hour maximum) makes it an insignificant factor in overall intake control. Gender, exercise type, intensity and duration may play a role in the occurrence of post-exercise anorexia.

A small number of studies have investigated potential changes in sensory responses and food preferences as a result of exercise. Preference ratings, tastiness and pleasantness of various foods can be affected following acute exercise. For example, low-fat, high-CHO lunch foods were rated more palatable after exercise than after rest in healthy women with dietary restraint, as assessed by the Three-Factor Eating Questionnaire ${ }^{21}$, though enhanced palatability did not affect intake ${ }^{15}$. Comparable observations were made in unrestrained women who rated foods more palatable after exercise $^{22}$, but not in males ${ }^{17}$.

After $30 \mathrm{~min}$ of moderate intensity cycling, sensory tests show that preference ratings for sucrose and citric acid solutions increase whereas there is no change in the palatability of $\mathrm{NaCl}$, caffeine or monosodium glutamate solutions ${ }^{23}$. The biological significance of such sensory responses and their potential impact on food selection and intake remain to be investigated.

When intensity and frequency of exercise become very high, then responses to gustatory and/or olfactory stimulation by foods can be disturbed. For example, female college swimmers and adolescent nonprofessional ballet dancers gave low palatability ratings for food stimuli with high fat and/or sugar concentrations, as is also observed in women with anorexia nervosa and bulimia ${ }^{24,25}$. The appearance, but not the flavour of meat products is rated higher than by male collegiate swimmers than by sedentary students ${ }^{26}$. In contrast to these performance-concerned groups, young American women who simply participate in various types of exercise for more than three hours per week found popcorn significantly more palatable than less active peers ${ }^{27}$.

The origin of these acute or chronic changes in sensory responsiveness is not known: though physiological processes may be involved, social and psychological factors can also contribute. This is particularly clear in the rejection by female amateur swimmers or dancers of sensory characteristics which signal high food energy content. The mechanism could rest in the strict dietary discipline that these individuals observe so as to optimize performance, rather than in the physiological effects of exercise per se.

\section{Food choices and exercise}

\section{Acute studies}

Homeostatic theories posit that substrates used by the organism for its various functions must be replaced by the ingestion of appropriate substances. The energy fuels used during exercise (glycogen and/or fat) should be specifically replaced by intake of $\mathrm{CHO}$ or fat. Consequently, exercise should elicit specific drives and exert a strong influence on subsequent food selection.

Most laboratory studies of food selection following exercise fail to show any strong effect on food choices. In particular, $\mathrm{CHO}$ intake is not enhanced following glycogen-depleting exercise $e^{12,14,16,17,28}$. There is no consistent evidence that the proportion of macronutrient oxidized (Respiratory Quotient) during exercise is matched by the proportion fo macronutrient consumed (Food Quotient) following exercise 15,19,29.

One laboratory has reported augmented intake, in particular of proteins, in meals served following athletics; this finding was not replicated after swimming ${ }^{30,31}$. The comparison of such results, obtained by the same group of investigators with closely similar methods, suggests the potential importance of the type of exercise on the effects observed. 


\section{Chronic effects}

When experimental training is continued over several weeks or months, some inconsistent alterations in the diet have been reported: e.g. decrease in fat intake ${ }^{32}$, increase in fat intake and decrease in $\mathrm{CHO}^{33}$. Gender and intensity of chronic training, among several factors, may affect the nutritional outcome. In people who report high levels of exercise as a part of their habitual lifestyle, surveys of food intake indicate selection of diets that are rich in $\mathrm{CHO}$, and reciprocally low in fat $^{10,34-38}$.

Under free-living circumstances, people select foods rather than nutrients. Very few studies have listed the actual changes in food selection that accompany varying levels of exercise. In 10-year-old French children, high activity levels were associated with a number of differences in daily eating behaviour ${ }^{10}$. The augmented $\mathrm{CHO}$ proportion in the diet of the most active children was attributable to more important intakes of bread and vegetables; yoghurt was also consumed in larger amounts by the most active children as compared with inactive peers. Meal patterns were also different, since the very active children ingested more energy at breakfast and in the traditional afternoon snack.

Adult men and women were surveyed for their regular physical activity and food choices, in two New England communities ${ }^{38}$. Although daily energy intake was not different in sedentary, moderately active and very active individuals, food choices and diet content were different. The latter two groups consumed less fat, and particularly less saturated fats than their more sedentary peers. Their diet contained more fibre and was richer in several vitamins, because of the selection of more fruits and vegetables. The active groups in this study also displayed other health-related behaviours, such as lower prevalence of smoking, deliberate attempts to limit fat and salt intake, etc. The regular practice of exercise seemed to be integrated in a 'healthy' lifestyle with dietary aspects. It may be hypothesized that a concern for health is at the origin of both exercise and diet charateristics.

Cottage cheese is consumed more often by runners than by inactive men in a North American sample, which is counterbalanced by a less frequent intake of red meat, bacon, sugar, jam and honey ${ }^{39}$. Success at fitness training is associated with less beef and coffee in middle-aged Americans ${ }^{40}$. Joggers of Japanese origin, living in Hawai, often use nutritionally modified diets and products (low-salt, energy-reduced, etc. ${ }^{41}$. Members of an American university running club control their intake of sugar and fat more than inactive peers ${ }^{42}$. In Finland, a five-year follow-up of adolescents showed, in males only, that a sedentary lifestyle was associated with a high proportion of saturated fatty acids in the daily $\operatorname{diet}^{37}$.

\section{Exercise and food choices in affluent societies}

One critical factor determining the interactions between exercise-induced energy expenditures and food intake, is the environmental context where they occur. Under free-living conditions, people select foods that are present in the immediate environment. The typical diet in Europe and America is very rich in fats which amount to $35-40 \%$ of daily energy. So active persons will have to select foods from a variety of products where fat is over-represented.

Food selection following exercise can compensate completely for the energy deficit corresponding to the cost of exercise, as demonstrated in laboratory studies where subjects could select from diets of varying fat content, following a bout of exercise. In 9 healthy males, energy intake was determined mainly by the fat content of the foods presented after exercise. Under a high fat condition ( $52 \%$ of energy), the amount of energy ingested completely cancelled the energy cost of exercise, leading to a positive energy balance after two days ${ }^{28}$; by contrast if the foods proposed were low in fat (30\% of energy), then an energy deficit was observed. Similar results were reported in men ${ }^{17}$ and in women ${ }^{15}$.

These observations illustrate the reason why exercise, even practised on a regular basis, does not lead to negative energy balance and body weight loss in affluent societies. The benefits exercise can be wiped out in minutes by the consumption of highenergy, high-fat foods abundantly present in the environment.

\section{Exercise, food choices and psychology}

The detailed description of the behavioural mechanisms that control food selection is beyond the scope of this review. Parameters of eating patterns, food preferences, ingestive responses in a particular environment are the results of learning mechanisms which have operated since birth, and perhaps during the foetal life. Potent biological learning mechanisms shape the acquisition of likes and dislikes ${ }^{11,43}$ in a specific socio-cultural context ${ }^{44}$. Food ingestion habits prove very resistant to acute changes in the environment ${ }^{45,46}$ or in physical activity ${ }^{18}$.

Two psychological factors seem to have special importance to determine the relationships of exercise and food choice in individual lives. One is the concern for health and body weight, the other is a psychological dimension which has attracted much attention in recent years: 'dietary restraint ${ }^{47}$.

People with a high level of concern for health are likely to make several consistent lifestyle choices, which include regular exercise and reasonable food selection. They are less likely to smoke than peers. In 
this context, the relationship between activity level and food choices appears to derive directly from the adoption by individuals of a healthy lifestyle with several dimensions; however, biological effects linking fuel expenditure and intake cannot be ruled out. Conversely, groups of people who exercise as little as possible, smoke and drink a lot, and have poor dietary selection have also been described ${ }^{48}$.

Dietary restraint is a chronic, relatively stable disposition to restrict food intake in order to control body weight. It is assessed by validated selfquestionnaires and various traits (hunger, disinhibition, emotionality, etc.) which contribute to it can be independently evaluated. Dietary restraint has been shown to affect eating behaviour in many circumstances. People with high levels of dietary restraint are likely to engage in more or less intense exercise, as a means to control body weight. An extreme example of this situation is anorexia nervosa, a behavioural disorder where emaciated patients exercise strenuously. Fortunately, this disease remains rare. However, dietary restraint is quite common especially among adolescent girls and women. Among the traits associated with restraint, disinhibition can have a decisive impact. A restrained person with a high disinhibition score is likely to give up all self-control and overeat in response to a variety of stimuli (alcohol, social context, etc.) called 'disinhibitors'. Exercise has been suggested to be one such disinhibitor ${ }^{15}$. The restrained person may become very vulnerable after exercise to external and internal influences susceptible to orient food selection and intake in the wrong direction.

Leisure-time athletes, like their professional models, are proposed several foods and drinks to improve their performances. Beside products that are especially designed and advertised as replacers of critical nutrients during exercise, low glycaemic-index $\mathrm{CHO}$ are recommended to active people who want to benefit from a sustained optimal level of energy during exercise. Professional and non-professional athletes are well aware that physical performance can be affected by food selection and intake. Once again, in this population, strong relationships exist between exercise and food choices; their origin may reflect psychological factors (knowledge, attitudes, motivation, etc.) as much as biological ones (need to replace glycogen stores, for example).

\section{Conclusions}

Though appetite is not affected by moderate intensity exercise, sensory responsiveness can be. Physiological hypotheses posit that regulatory mechanisms could come into play to increase the drive to consume food sources of the fuel (CHO and/or fat) used during exercise $^{7,49-51}$. However, experimental works yield inconsistent results, and there are examples where $\mathrm{CHO}$, or fats, or proteins are consumed in greater amounts after exercise. Regular exercise that is practised as a stable element of lifestyle is often associated with high $\mathrm{CHO}$ intake and/or low fat intake. Discordant results are also numerous, where training leads to increased fat and/or decreased $\mathrm{CHO}$ intake $26,33,52-54$. Whether these effects are based on biological mechanisms ${ }^{8}$ or cognitive influences ${ }^{4}$ is not known.

Very few studies actually assess food choices in active versus sedentary people. Cereal products such as bread, fruits, and vegetables appear often in the diet of active adults and children. A critical public health message derived from the experimental studies about exercise and food selection is that the intake of high-fat foods can easily cancel all beneficial effects of exercise on energy balance. In societies where the typical diet is very rich in fats, exercise can help in body weight control only with appropriate food selection. Selection of palatable fat foods can be 'disinhibited' after exercise. The public should be made aware that food choices determine whether the energy expended over long hours of physical activity will actually help in the control of body weight.

Exercise of different intensity, in people of different gender and age, with varying psychological sets, is likely to interact in very different ways with diet. More research is needed on the specific effects of specific levels of exercise in specific populations. Exercise in the context of weight control programmes has complex interactions with diet which deserve careful investigation.

\section{References}

1 Hardman A. Physical activity. In: Healthy Lifestyles Nutrition and Physical Activity. ILSI Europe Concise Monograph Series. Brussels:ILSI, 1998, 40-6.

2 Blundell JE, King NA. Effects of exercise on appetite control: loose coupling between energy expenditure and energy intake. Int.J. Obes. 1998; 22(suppl. 2): S22-9.

3 Bouchard C, Després JP, Tremblay A. Exercise and obesity. Ob. Res. 1993; 1: 133-47.

4 Hill JO, Melby C, Johnson SL, Peters JC. Physical activity and energy requirements. Am. J. Clin. Nutr. 1995; 62(Suppl): 1059S-66S.

5 King NA. The relationship between physical activity and food intake. Proc. Nutr. Soc. 1998; 57: 77-84.

6 King NA, Tremblay A, Blundell JE. Effects of exercise on appetite control: implications for energy balance. Med. Sci. Sports Exerc. 1997; 29: 1076-89.

7 Richard D. Exercise and the neurobiological control of food intake and energy expenditure. Int.J. Obes. 1995; 19(suppl. 4): $\mathrm{S} 73-9$

8 Tremblay A, Alméras N. Exercise, macronutrient preferences and food intake. Int. J. Obes. 1995; 19(suppl. 4): S97-101.

9 Prentice AM, Black AE, Coward WA, Davies HL, Goldberg GR, Murgatroyd PR, Ashford J, Sawyer M, Whitehead RG. 
High levels of energy expenditure in obese women. $\mathrm{Br}$. Med. J. 1986; 292: 983-7.

10 Deheeger M, Rolland-Cachera MF, Fontvieille AM. Physical activity and body composition in 10 year old French children: linkages with nutritional intake? Int. J. Obes. 1997; 21: 372-9.

11 Le Magnen J. Neurobiology of Feeding and Nutrition. San Diego: Academic Press, 1992.

12 Reger WE, Allison TA, Kurucz RL. Exercice, post-exercice metabolic rate and appetite. Sport Health Nutr. 1986; 2: 117-23.

13 Reger WE, Alison TG. Exercise and appetite. Med. Sci. Sports Exerc. 1987; 19: S38.

14 Thompson DA, Wolfe LA, Eikelboom R. Acute effects of exercise intensity on appetite in young men. Med. Sci. Sports Exerc. 1988; 20: 222-7.

15 LLuch A, King NA, Blundell JE. Exercise in dietary restrained women: no effect on energy intake but change in hedonic ratings. Eur. J. Clin. Nutr. 1998; 52: 300-7.

16 King NA, Burley VJ, Blundell JE. Exercise-induced suppression of appetite: Effects on food intake and implications for energy balance. Eur. J. Clin. Nutr. 1994; 48: 15-724.

17 King NA, Blundell JE. High-fat foods overcome the energy expenditure due to exercise after cycling and running. Eur. J. Clin. Nutr. 1995; 49: 114-23.

18 Hubert P, King NA, Blundell JE. Uncoupling the effects of energy expenditure and energy intake: appetite response to short-term energy deficit induced by meal omission and physical activity. Int. J. Obes. 1997; 21(Suppl.): P125.

19 King NA, LLuch A, Stubbs RJ, Blundell JE. High dose exercise does not increase hunger or energy intake in free living males. Eur. J. Clin. Nutr. 1997; 51: 478-83.

20 Kissileff HR, Pi-Sunyer X, Segal K, Meltzer S, Foelsch PA. Acute effects of exercise on food intake in obese and nonobese women. Am. J. Clin. Nutr. 1990; 52: 240-5.

21 Stunkard AJ, Messick S. The Three-Factor Eating Questionnaire to measure dietary restraint, disinhibition and hunger. J. Psychosom. Res. 1985; 29: 71-83.

22 King NA, Snell L, Smith RD, Blundell JE. Effects of short-term exercise on appetite responses in unrestrained females. Eur. J. Clin. Nutr. 1996; 50: 663-7.

23 Horio T, Kawamura Y. Influence of physical exercise on human preferences for various taste solutions. Chem. Senses 1998; 23: 417-21.

24 Martin C, Bellisle F. Eating attitudes and taste responses in young ballerinas. Physiol. Behav. 1989; 46: 223-7.

25 Crystal S, Frye CA, Kanarek RB. Taste preferences and sensory perceptions in female varsity swimmers. Appetite. 1995; 24: 25-36.

26 Guinard JX, Seador K, Beard JL, Brown PL. Sensory acceptability of meat and dairy products and dietary fat in male collegiate swimmers. Int.J. Sport Nutr. 1995; 5: 315-28.

27 Kanarek RB, Ryu M, Przypek J. Preferences for foods with warying levels of salt and fat differ as a function of dietary restraint and exercise but not menstrual cycle. Physiol. Behav. 1995; 57: 821-6.

28 Tremblay A, Alméras N, Boer J, Kranenbarg EK, Després JP. Diet composition and postexercise energy balance. Am. J. Clin. Nutr. 1994; 59: 975-9.

29 Snitker S, Larson DE, Tataranni PA, Ravussin E. Ad libitum food intake in humans after manipulation of glycogen stores. Am. J. Clin. Nutr. 1997; 65: 941-6.

30 Verger P, Lanteaume MT, Gournay JF, Louis-Sylvestre J. Choix alimentaire spontané après un exercice physique de natation. Méd. Nutr. 1992; 28: 73-7.

31 Verger P, Lanteaume MT, Louis-Sylvestre J. Free food choice after acute exercise in men. Appetite 1994; 22: 159-64.

32 Bryner RW, Toffle RC, Ullrich IH, Yeater RA. The effects of exercise intensity on body composition, weight loss, and dietary composition in women. J. Am. College Nutr. 1997; 16: $68-73$.
33 Ambler C, Eliakim A, Brasel JA, Lee WNP, Burke G, Cooper DM. Fitness and the effect of exercise training on the dietary intake of healthy adolescents. Int. J. Obes. 1998; 22: 354-62.

34 Bjorntorp P. Exercise in the treatment of obesity. Clin. Endocrinol. Metab. 1976; 42: 69-82.

35 Saris WHM. Physiological aspects of exercise in weight cycling. Am. J. Clin. Nutr. 1989; 49: 1099-104.

36 Hardman AE. Exercise and Health. CHO Internal. Dialogue. 1991; 2: 3 .

37 Raitakari OT, Porkka KVK, Taimela S, Telama R, Räsänen L, Viikari JSA. Effects of persistent physical activity and inactivity on coronary risk factors in children and young adults. Am. J. Epidemiol. 1994; 140: 195-205.

38 Eaton CB, McPhillips JB, Gans KM, Garber CE, Assaf AR, Lasater TM, Carleton RA. Cross-sectional relationship between diet and physical activity in two southeastern New England communities. Am.J. Prev. Med. 1995; 11: 23844.

39 Hartung GH, Foreyt JP, Mitchell RE, Vlasek I, Gotto AM Jr. Relation of diet to high-density lipoprotein cholesterol in middle-aged marathon runners, joggers, and inactive men. N. Engl. J. Med. 1980; 302: 357-61.

40 Blair SN, Goodyear NN, Wynne KL, Saunders RP. Comparison of dietary and smoking habit changes in physical fitness improvers and nonimprovers. Prev. Med. 1984; 13: 41120.

41 Yamamoto L, Yano K, Rhoads G. Characteristics of jogging among Japanese men in Hawai. Am. J. Pub. Health. 1983; 73: $147-52$.

42 Zunich EM, Dickinson AA. A comparison of physical fitness, behaviors of joggers and non-joggers. Health Values. 1979; 3: 296-9.

43 Birch LL. Development of food acceptance patterns. Devel. Psychol. 1990; 26: 515-19.

44 Rozin P. Towards a Psychology of Food Choice. Danone Chair Monograph. Brussels: Danone, 1998.

45 Stubbs RJ, Harbron CG, Murgatroyd PR, Prendice AM. Covert manipulation of dietary fat and energy density: effect on substrate flux and food intake in men eating ad libitum. Am. J. Clin. Nutr. 1995; 62: 316-29.

46 Stubbs RJ, Ritz P, Coward WA, Prentice AM. Covert manipulation of the ratio of dietary fat to carbohydrate and energy density: effect on food intake and energy balance in free-living men eating ad libitum. Am. J. Clin. Nutr. 1995; 62: 330-7.

47 Herman CP, Polivy J. Restrained eating. In: Stunkard AJ, ed. Obesity. Philadelphia: Saunders, 1980: 208-25.

48 Kirk TR, Soulsby C. Diet and alcohol intake: a study amongst male university students. Proc. Nutr. Soc. 1991; 50: 103A.

49 Stanley BG, Lanthier D, Chin AS, Leibowitz SF. Suppression of neuropeptide-Y-elicited eating by adrenalectomy or hypophysectomy-reversal with corticosterone. Brain Res. 1989; 501: 32-6.

50 Tremblay A, Després JP, Bouchard C. The effects of exercisetraining on energy balance and adipose tissue morphology and metabolism. Sports Med. 1985; 2: 223-33.

51 Flatt JP. Dietary fat, carbohydrate balance, and weight maintenance: effects of exercise. Am.J. Clin. Nutr. 1987; 45: 296-306.

52 Parizkova J, Poupa O. Some metabolic consequences of adaptation to muscular work. Br. J. Nutr. 1963; 17: 341-5.

53 Kiens B, Jorgensen I, Lewis S, Jensen G, Lithell J. Increased plasma HDL-cholesterol and apo A-1 in sedentary middleaged men after physical conditioning. Eur. J. Clin. Invest. 1980; 10: 203-9.

54 Reggiani E, Bertolini S, Chiodini G. Effects of physical activity and diet on lipemic risk factors for atherosclerosis in women. Int. J. Sports Med. 1984; 5: 183-6. 